\title{
Examining the Relation between Emotional Intelligence and Happiness Status of Wellness Trainers
}

\author{
Ercan ZORBA ${ }^{1}$, Adem PALA $^{1}$ \& Ali Gürel GÖKSEL ${ }^{1}$ \\ ${ }^{1}$ Mugla Sitki Kocman Universtiy, Faculty of Sports Science, Mugla, Turkey \\ Correspondence: Adem PALA, Mugla Sitki Kocman Universtiy, Faculty of Sports Science, 48000, Mugla, \\ Turkey. Tel: 90-555-746-5861. E-mail: ademmpala@hotmail.com
}

\author{
Received: April 16, 2016 \\ Accepted: May 5, 2016 Online Published: May 30, 2016 \\ doi:10.5539/jel.v5n3p159 \\ URL: http://dx.doi.org/10.5539/jel.v5n3p159
}

\begin{abstract}
The purpose of this study is examining the relation between the emotional intelligence and happiness of the wellness coaches. 390 wellness coaches 282 of whom were women and 108 of whom were men participated voluntarily in the study. The participants were actively working as wellness coaches. The Emotional Intelligence Scale (EIS) whose Turkish adaptation was realized by Aslan; and the Oxford Happiness Scale, which was developed by Hills and Argyle whose adaptation into Turkish was realized by Dogan and Sapmaz were used as the data collection tools. The descriptive statistical methods, the t-test, One-Way Variance Analysis (ANOVA), regression analysis and Pearson Correlation tests were used for the analysis of the data. At the end of the study it was determined that there was no statistically significant differences between the happiness and emotional intelligence points of Wellness Coaches for Oxford Happiness Scale when these points were compared according to the genders $(p>0,05)$; and significant difference was determined in benefiting from emotions and optimism, which are the sub-dimensions of emotional intelligence scale $(p<0,05)$; no statistically significant differences were found in the sub-dimension of the expression of emotions $(p>0,05)$. It is observed that there is a positive relation at 0,383 level between the Oxford Happiness Scale and the Emotional Intelligence Scale. When the regression analysis results are examined, it is observed that the Emotional Intelligence Sub-dimensions explain the happiness at the medium level. The most explanatory one among the sub-dimensions is the optimism sub-dimension.
\end{abstract}

Keywords: wellness, trainer, emotional intelligence, happiness

\section{Introduction}

Happiness has emerged as a concept that has always been shaped according to the requirements of the current age and different demands in all periods of history, and has become a concept that is wanted more in modern societies with the changes experienced throughout history (Baysal \& Aka, 2013). This concept, which is used by us as happiness in everyday colloquial language, is used as a synonym of being subjectively well in the literature (Diener, 2000). Happiness or being subjectively well is the superiority of the positive thoughts and emotions in number about the life of a person (Myers \& Diener, 1995), in other words, it is the sum of the satisfaction and positive emotions received by the individuals from their lives (Kangal, 2013).

With the broadest meaning, happiness may be defined as the positive evaluation of the total quality of one's life (Bulbul \& Giray, 2011), and the increase of happiness brings multiple benefits for an individual (Schiffrin \& Nelson, 2010). The increase of happiness for an individual is important in that it makes it possible for the individual to live healthily in psychological terms and to be successful in academic, social and professional life (Asici \& Ikiz, 2015).

People with social skills are the ones who do not prepare the ground for negative emotions that prevent the cooperation of himself/herself of the other people around and who are able to manage conflicts efficiently in a kind and able manner (Mayer, Salovey, \& Caruso, 2004). This fine-tuned management has guided the individual to a wider concept, which has been discussed as of 1990s and which covers social skills (Aslan, 2008). This new concept is the concept of emotional intelligence. 
Emotional intelligence is the skill of arranging the emotions for the purpose of supporting the emotional and intellectual growth, perceiving and evaluating the emotions, forming the emotions that facilitate thinking, understanding emotions and emotional knowledge (Mayer \& Salovey, 1997).

Goleman (1995), who conducted important studies on emotional intelligence, defined it as "being able to activate oneself, going on despite negative events, delaying satisfaction by controlling one's urges, organizing one's spiritual status, not allowing the distresses preventing oneself from thinking, putting oneself in another's place, and having hopes..."

The individuals are improving themselves as coaches and instructors in wellness branch, which is a new concept in World. It is considered that these individuals' feeling happy is related with emotional intelligence. These factors are important in influencing the followers of coaches. In this context, it was aimed that the emotional intelligence and happiness status (subjective wellbeing) of wellness coaches are determined.

The relationship emotional intelligence and happiness status has been researched many study such as Tingaz (2013) have worked about teachers' happiness status and emotional intelligence, this study constituted our starting point. We want to explore this interesting topis from different different perspective. Former studies have generally examined comparison of these variables but we investigated that relationship between emotional intellingence and happiness.

\section{Method}

\subsection{The Method of the Study}

The study was conducted with relational scanning model, which is one of the general scanning models. "Scanning Models are the research approaches that aim to describe an existing or past situation as is" (Karasar, 2000). "Relational scanning models aim to determine the existence or the level of the co-variation between two or more variables" (Karasar, 2000).

\subsection{The Universe and the Sampling of the Study}

The universe of the study consists of the 2512 individuals who have 1st Level Wellness Coach certificates as of January 2016 in Sports for Everyone Federation. It was determined that 333 wellness coaches were needed to represent the universe of this study with a $5 \%$ error rate and with $95 \%$ confidence interval. By considering the possible problems in return rates, the purpose was including 500 wellness coaches in the sampling. For this reason, 487 wellness coaches, who volunteered to support the study, and who participated in the 2nd Level Wellness Coach Seminar, which was organized by Sports for Everyone Federation. A questionnaire was applied to the participants by using simple random sampling technique. In this context, 390 active wellness coaches, 282 of whom were women, and 108 were men, who had 1st Level Wellness Coaching Certificates were included in the study as the sampling group. The questionnaires of these participants did not have unanswered questions, and the same options were not marked continuously.

\subsection{Data Collection Tool}

In order to obtain the proper data for the purpose of the study, the Personal Information Form, which consists of demographic questions prepared by the authors and the Emotional Intelligence Scale (EIS), which was given the last form by Austin et al. (2004) and which was adapted to Turkish by Aslan (2008); and the Oxford Happiness Scale (OHS), which was developed by Hills and Argyle (2002) and improved by Dogan and Sapmaz (2012) by adapting it into Turkish language, used. The detailed information on EIS and OHS is provided below.

Emotional Intelligence Scale: Schutte et al. (1998) scale includes 33 items and is a single-dimensional one. The scale includes the topics like understanding and expressing the emotions of oneself or the others, adjusting the emotions of one's of the others', and using them in solving problems. Schutte et al. (1998) reported that the reliability of this scale is high (Cronbach Alpha value: .87-.90). It was understood that the scale of Schutte consisting of 33 questions, which was used as a single-dimensional scale in various scales, was structured as three or four-dimensional scale. The most important studies among these are the one conducted by Austin et al. (2004). In this study, Schutte et al. found the internal reliability coefficient of the 33-question initial scale as $(\alpha ; .84)$; however, later on, it was revised and the number of the questions was raised to 41 questions, and a 3 dimensional scale was suggested consisting of "adjusting the status of the spirit", "the use of emotions", "evaluation of the emotions". Aslan (2008) conducted a study and examined the validity and reliability of the single-factor structure and then the three or four factor structure based on the previous studies. The scale was rated by using the 5-Point Likert Scale (1=I strongly disagree, 5=I strongly agree) (Akgul \& Cevik, 2003). For 
this study, the reliability value of each factor (Cronbach Alpha) were $0.77,0.78$, and 0.75 , respectively. These values show that the dimensions of the scale are reliable $(0.60<\alpha)$.

Oxford Happiness Scale: The happiness scale was developed by Hills and Argyle (2002) and consists of 29 items. Hills and Argyle (2002) determined the internal consistency coefficient of the scale (Cronbach Alpha) as 0.91. The points that may be received from the scale vary between 29 and 145. As the points received from the scale increase, so does the happiness level. For this study, the reliability value (Cronbach Alpha) was measured as 0,786 .

The data were collected with face to face meeting and questionnaires filled out by participants.

\subsection{The Analysis of Data}

The data which were obtained from the answers given to the questions in the questionnaire by the wellness coaches were analyzed by using descriptive statistical methods, t-test, One-Way Variance Analysis (ANOVA), Tukey multiple comparisons test, regression analysis and Pearson Correlation test. The issue of whether the data covered the pre-condition of the parametric tests was decided on examining the Skewness and Kurtosis (normal distribution status) values, and Levene (equality of the variances) test results.

\section{Results}

Table 1. The distribution of the points received from the scales

\begin{tabular}{lllll}
\hline Scale & $\mathrm{n}$ & $\bar{X}-\sigma$ & Skewness & Kurtosis \\
\hline EIS & 390 & $9,35-, 77$ & $-0,51$ & 0,24 \\
OHS & 390 & $3,65-, 50$ & $-0,22$ & 0,16 \\
\hline
\end{tabular}

The arithmetic average values of the points received from the Oxford Happiness Scale and Emotional Intelligence Inventory by the participants were found as 9,35-,77 and 3,65-,50. When the skewness and lowness coefficients are examined, it was observed that the data collected from the participants showed a normal distribution (Table 1).

Table 2. Demographic information of participant

\begin{tabular}{lcc}
\hline Variables & $\mathrm{N}$ & $\%$ \\
\hline Gender & 282 & $72,3 \%$ \\
Male & 108 & $27,7 \%$ \\
Female & 390 & $100 \%$ \\
Total & & \\
Age & 298 & $76,4 \%$ \\
$20-25$ & 54 & $13,8 \%$ \\
$26-31$ & 38 & $9,7 \%$ \\
$32-34$ & 390 & $100 \%$ \\
Total & & \\
\hline
\end{tabular}


Table 3. Comparison of happiness and emotional intelligence points according to gender of the participants

\begin{tabular}{llllll}
\hline Variable & Gender & $\mathrm{N}$ & $\bar{X}-\sigma$ & $\mathrm{t}$ & $\mathrm{p}$ \\
\hline \multirow{2}{*}{ OHS } & Women & 282 & $3,64-, 51$ &,- 520 &, 603 \\
\multirow{2}{*}{ EIS Sub-Dimensions } & Men & 108 & $3,67-, 46$ & & \\
\multirow{2}{*}{ Optimism } & & & & & \\
& Women & 282 & $3,86-, 43$ & $-3,707$ &, $000^{*}$ \\
Making use of Emotions & Men & 108 & $4,04-, 42$ & & \\
& Women & 282 & $2,75-, 56$ & 3,196 & \multirow{2}{*}{, $002^{*}$} \\
& Men & 108 & $2,54-, 57$ & & \\
& Women & 282 & $2,75-, 41$ & 1,122 & \multirow{2}{*}{, 262} \\
\hline
\end{tabular}

When the happiness and emotional intelligence points of the wellness coaches were compared according to the gender variable it was observed that no statistically significant difference was determined for the Oxford Happiness Scale $(\mathrm{p}>0,05)$; significant differences were found for the sub-dimensions of the Emotional Intelligence Scale like Making use of Emotions and Optimism $(p<0,05)$; and no statistically significant differences were found in the sub-dimension of Expressing the Emotions $(p>0,05)$.

Table 4. Comparison of happiness and emotional intelligence points according to age of the coaches

\begin{tabular}{llllll}
\hline Variable & Age & $\bar{X}-\sigma$ & $\mathrm{p}$ & Post Hoc & $\mathrm{F}$ \\
\hline \multirow{2}{*}{ OHS } & $20-25$ & $3,66-, 51$ & & & \\
& $26-31$ & $3,62-, 52$ &, 859 & & \\
EIS & $31-36$ & $3,63-, 40$ & & & \\
Sub-Dimensions & & & & & \\
& $20-25$ & $3,90-, 40$ & & & 1,050 \\
Optimism & $26-31$ & $3,89-, 62$ &, 351 & & \\
& $31-36$ & $4,01-, 35$ & & & \\
& $20-25$ & $2,72-, 56$ & & $20-25>26-31$ & \\
Making use of & $26-31$ & $2,40-, 53$ & $0,00^{*}$ & $32-37>20-25$ & \\
Emotions & $31-36$ & $2,86-, 58$ & & & \\
& $20-25$ & $2,77-, 42$ & & $20-25>32-37$ & \\
Expression of & $26-31$ & $2,60-, 38$ & $0,03 *$ & & \\
Emotions & $31-36$ & $2,59-, 42$ & & & \\
& & & & & \\
\hline
\end{tabular}

When the happiness and emotional intelligence points of the wellness coaches were compared according to the age variable it was observed that there was no statistically significant differences for the Oxford Happiness Scale $(\mathrm{p}>0,05)$; but a significant difference was found between the Making use of Emotions and Expression of Emotions sub-dimensions, which are the sub-dimensions of Emotional Intelligence Scale $(p<0,05)$. While this difference was found for the Making Use of Emotions sub-dimension for 20-25 and 32-37 ages, it was observed that the results were in favor of the coaches between the 20-25 age range in the Expression of Emotions sub-dimension. No statistically significant difference was found in Optimism sub-dimension, which is another sub-dimension of Emotional Intelligence Scale $(\mathrm{p}>0,05)$. 
Table 5. The relation between Happiness Scale and Emotional Intelligence Scale

\begin{tabular}{llll}
\hline & & OHS & EIS \\
\hline \multirow{3}{*}{ OHS } & Pearson Correlation & 1 &, $383^{* *}$ \\
& Sig. (2-tailed) & &, 000 \\
& $\mathrm{~N}$ & 390 & 390 \\
\multirow{2}{*}{ EIS } & Pearson Correlation &, $383^{* *}$ & 1 \\
& Sig. (2-tailed) &, 000 & \\
& $\mathrm{~N}$ & 390 & 390 \\
\hline
\end{tabular}

When Table 4 is examined, it is observed that there is a positive relation between Oxford Happiness Scale and Emotional Intelligence Scale at 0,383 level.

Table 6. Regression analysis results

\begin{tabular}{lcccllll}
\hline $\begin{array}{l}\text { Dependent } \\
\text { Variable }\end{array}$ & $\begin{array}{c}\text { Independent } \\
\text { Variable }\end{array}$ & $\beta$ & $\mathrm{t}$ & $\mathrm{p}$ & $\mathrm{F}$ & Model (P) & $\mathrm{R} 2$ \\
\hline \multirow{4}{*}{ Happiness } & Fixed &, 935 & 2,989 &, $003^{*}$ & & & \\
& Optimism &, 468 & 8,648 &, $000^{*}$ & 60,510 &, $000^{*}$ &, 439 \\
& Making use of Emotions &, 322 & 7,956 &, $000^{*}$ & & & \\
& Expression of Emotions & 0,08 &, 147 & 0,883 & & & \\
\hline
\end{tabular}

When the Regression analysis results were examined it was observed that emotional intelligence sub-dimensions explained happiness at medium level. The most explanatory one among the sub-dimensions is the optimism sub-dimension $(\beta=0,468)$. Making use of emotions and expressing of emotions sub-dimensions follow these dimension $(\beta=0,322, \beta=0,08$, respectively).

\section{Conclusion and Discussion}

When the happiness and emotional intelligence points of the wellness coaches are compared according to the gender variable, no statistically significant differences were detected for Oxford Happiness Scale $(p>0,05)$. Tingaz and Hazar (2014) conducted a study on university students and found that there were no statistically significant differences, which supported our study. Aydemir's (2008) study and the results of his study supported our study. However, Gokdemir and Dumludag (2010) have researched a study on the Turks who lived in Netherlands and reported significant differences between men and women, which is unlike the results of our study. Significant difference was found in the making use of emotions and optimism sub-dimensions for Emotional Intelligence Scale $(\mathrm{p}<0,05)$; and no statistically significant differences were found in expressing emotions sub-dimension ( $p>0,05)$. Again, Tingaz and Hazar (2014) conducted a study and did not find significant difference for the optimism sub-dimension, which is unlike our results. Certel et al. (2011) conducted a study on physical education coaches and reported that the gender factor was not influential on general spiritual status sub-dimension of the emotional intelligence level. Parallel to this study, Taskin et al. (2010) conducted a study on physical education students reported that there were no differences between men and women in the personal skills and agreement factors, which are among the emotional intelligence sub-dimension.

When the happiness and emotional intelligence points of the wellness coaches were compared according to the age variable it was observed that there were no statistically significant difference for Oxford Happiness Scale $(\mathrm{p}>0,05)$; however, significant difference was found in the Making use of Emotions and Expressing Emotions sub-dimensions, which are the sub-dimensions of Emotional Intelligence Scale $(p<0,05)$. This difference was found for Making use of Emotions sub-dimension for 20-25 and 32-37 ages, and it is in favor of the coaches between the 20-25 age group for expressing emotions sub-dimension. In the Optimism sub-dimension, which is another sub-dimension of Emotional Intelligence Scale, no statistically significant differences were found $(p>0,05)$. Harrod and Scheer (2005) conducted a study on the emotional intelligence levels of students and found significant difference for age factor. Zekioğlu et al. (2015) conducted another study and reported statistically significant differences between the emotional intelligence and ages of the students. In the study of Adiloğulları et 
al. (2014), which aimed to determine the difference between the emotional intelligence of teachers and their ages, it was reported that there were significant differences between the emotional intelligence of the participants and their ages, which is parallel to our study. Again, in the study which was conducted by Adiloğulları in 2011, no significant difference was found for the age variable, which is unlike our study.

It is observed that there is a positive relation at 0,383 level between the Oxford Happiness Scale and Emotional Intelligence Scale. When the regression analysis results are examined it is observed that emotional intelligence sub-dimension influence happiness at a medium level. The most explanatory one among the sub-dimensions is the optimism sub-dimension $(\beta=0,468)$. Making use of emotions and expressing emotions sub-dimensions follow this dimension ( $\beta=0,322, \beta=0,08$, respectively).

\section{References}

Adilogullari, I. (2011). The teachers level of emotional intelligence some of the demographic variables for investigation. Educational Research and Reviews, 6(13), 786-792.

Adilogullari, I., Ulucan, H., \& Senel, E. (2014). Analysis of the relationship between the emotional intelligence and professional burnout levels of teachers. Educational Research and Reviews, 9(1), 1-8. http://dx.doi.org/10.5897/ERR2013.1670

Akgul, A., \& Cevik, O. (2003). Technical statical analysis, SPSS practice of business management. Ankara: Emek Ofset Ltd. Sti.

Aslan, S. (2008). Is there any relationshıp between emotional intelligence and conflict handling styles? The study of validity and realibility Schutte's EQ inventory. Suleyman Demirel University The Journal of Faculty of Economics and Administrative Sciences, 13(3), 179-200.

Asici, E., \& Ikiz, F. E. (2015). A pathway to happiness: Cognitive flexibility. Mehmet Akif Ersoy University Journal of Education Faculty, 35, 191-211.

Austin, E. J., Saklofske, D. H., Huang, S. H. S., \& Mckenney, D. (2004). Measurement of trait emotional intelligence: Testing and cross validating a modified version of Schutte et al.'s (1998) Measure. Personality and Individual Differences, 36, 555-562. http://dx.doi.org/10.1016/S0191-8869(03)00114-4

Aydemir, R. E. (2008). Relationship happiness and piety (Master thesis). Ondokuzmayis University Social Science, Samsun.

Baysal, S., \& Aka, I. C. (2013). Usage of happiness theme as a marketing strategy by brands: A survey on happiness based marketing. Sosyal ve Beseri Bilimler Dergisi, 5(1), 84-93.

Bulbul, S., \& Giray, S. (2011). Analysis of the relationship structure between socio-demographic features and happiness sensation. Ege Academic Review, 11, 113-123.

Certel, Z., Catikkas, F., \& Yalcinkaya, M. (2011). Analysis of the emotional intelligence levels and critical thinking dispositions of physical education teacher candidates. Selcuk University Journal of Physical Education and Sport, 13(1), 74-81.

Diener, E. (2000). Subjective well-being, the science of happiness and a proposal for a national index. American Psychologist, 55(1), 34-39. http://dx.doi.org/10.1037/0003-066X.55.1.34

Dogan, T., \& Sapmaz, F. (2012). Examination of psychometric properties of the Turkish version form of the Oxford Happiness Questionnaire in university students. Dusunen Adam The Journal of Psychiatry and Neurological Sciences, 25(4), 297-304.

Goleman, D. (1995). Emotional Intelligence: Why It Can Matter More Than IQ? London: Bloomsbury Publishing.

Gokdemir, O., \& Dumludag, D. (2010). Happiness among Turkish and Moroccan Immigrants in the Netherlands. International Journal of Interdisciplinary Social Sciences, 5(6), 155-166.

Harrod, N. R., \& Scheer, S. D. (2005). An exploration of adolescent emotional intelligence in relation to demographic characteristics. Adolescence, 40, 503-512.

Hills, P., \& Argyle, M. (2002). The Oxford happiness questionnaire: A compact scale for the measurement of psychological well-being. Personality and Individual Differences, 33, 1073-1082. http://dx.doi.org/10.1016/S0191-8869(01)00213-6

Kangal, A. (2013). A conceptual review on happiness and some consequences for Turkish household. Electronic Journal of Social Sciences, 12(44), 214-233. 
Karasar, N. (2000). Scientific method of research. Ankara: Nobel Transportation.

Mayer, J. D., \& Salovey, P. (1997). Emotional development and emotional intelligence (1st ed.). New York: Basic Books.

Mayer, J. D., Salovey, P., \& Caruso, D. R. (2004). Emotional intelligence: Theory, findings and implications. Psychological Inquiry, 15(3), 197-206. http://dx.doi.org/10.1207/s15327965pli1503_02

Myers, G. D., \& Diener, E. (1995). Who is happy? Psychological Science, 6(1), 10-19. http://dx.doi.org/10.1111/j.1467-9280.1995.tb00298.x

Schiffrin, H. H., \& Nelson, K. S. (2010). Stressed and happy? Investigating the relationship between happiness and perceived stress. Journal of Happiness Studies, 11, 33-39. http://dx.doi.org/10.1007/s10902-008-9104-7

Schutte, N. S., Malouff, J. M., Hall, L. E., Haggerty, D. J., Cooper, J. T., Golden, C. J., \& Dornheim, L. (1998). Development and validation of a measure of emotional intelligence. Personality and Individual Differences, 25, 167-177. http://dx.doi.org/10.1016/S0191-8869(98)00001-4

Taskin, A. K., Tasgin O., Basaran, M. H., \& Taskin, C. (2010). Examine of emotional intelligence levels on physical education students according to some variables. Selcuk University Journal of Physical Education and Sport, 12(2), 98-103.

Tingaz, E. O., \& Hazar, M. (2014). The comparison of emotional intelligence and happiness of the preservice teachers in the department of physical education and sports teaching with some preservice teachers in other departments. International Journal of Science Culture and Sport, 745-756.

Zekioglu, A., Tatar, A., \& Turkmen, M. (2015). Comparing of emotional intelligency according to gender among students of School of Physical Education and Sport. Uhbab Journal, 4(11), 62-69. http://dx.doi.org/10.17368/uhbab.2015118896

\section{Copyrights}

Copyright for this article is retained by the author(s), with first publication rights granted to the journal.

This is an open-access article distributed under the terms and conditions of the Creative Commons Attribution license (http://creativecommons.org/licenses/by/3.0/). 